\title{
THE IMPORTANCE OF TEACHING LITERATURE TO STUDENTS
}

\author{
Ista Maharsi \\ Universitas Islam Indonesia Yogyakarta
}

\begin{abstract}
Literature, in its own self, possesses rich heritage, social, political, philosophical, and economical reflection of an era. It has long been used to depict various circumstances, sound social critiques on a particular condition, reflect characteristics of an age, portray culture of a society, and reveal conspiracy in a country. Literature is widely learned and discussed in schools, yet its benefits and values are often questioned. This paper is aimed to elaborate the idea of the necessity of teaching literature to students and how it can be bought into classrooms.
\end{abstract}

Key words: literature, language, values, students

\section{INTRODUCTION}

Literature has been widely acknowledged since a long time ago and studied in all over the world. Also, literature was commonly, in the old time, wellcomprehended and well known among teenagers and adult people, indeed. As Ohmann notes in his excerpt that "Our classrooms filled up during the fifties and sixties, as students left the sciences and sought insight through the arts....." Great literature was taught and intensively discussed in both formal and non formal schools, as the appreciation of literature was still in its golden glory and of high honored value. Besides, history has considerably revealed the fact that 'canon', as people referred to the masterpieces, is the significant core existence which needs to be maintained, respected, taught, and put it in everyone's mind just like our mind is always mingled with value of life itself. Or else, some people might keep it in their house, definitely not as a decoration of book shelf, but rather in the extreme sense as 'guidance' of valuing bad and good. Thus, a questioning on whether literature is still needed to be passed on to the next generations as a means "for developing and refining the intelligent" or because of its moral value density continues to be 'the 
rolling ball discussion'(Ohmann, 2004). Therefore, whether literature can be brought to classrooms and passed on to the next generation meaningfully lies on the hands of teachers. McKay clarifies that there are two main cores of literature-linguistic and conceptual (1982, p.530). Therefore, there are also two importance issues that become the centers o literature, namely the language and the ideas, thoughts, concepts, messages, and values condensed in it.

\section{LITERATURE: THE VALUES WITHIN}

Many, rather than most, of students seem to wonder of the reason of being given literature as one of their subjects. Unluckily, the questions are left unanswered as no one would eagerly explain why, and so would the teachers. The tradition of teaching literature to students has been lasting for decades, yet there has been no evidence that by learning literature students become more intelligent and of better moral value.

E.L. Marson states the importance of literature as "carves upon the bedrock of humanity, reflecting man and his world..."(1969, p.10). It is indeed true that literature is part of human culture which is cultivated from the power of language usage and that language, on the one hand, is the basic idea which differentiates human from other creatures (Poole, 1999, p. 3). On the other hand, language functions as a means of expressing feeling and responses. To put it simply, a writer communicates his ideas to the reader through his literary works and the reader gives response to the work through literary criticism. In this case, students are positioned as the readers in the sense that they are studying literature at schools and then analyzing it. The results then will be likely to have various different feedbacks. Some might be very critical in the language usage of imagery or metaphor while the others might be genius to interpret the works by relating them to the external aspects from which they were born. Again, Marson (1969, p.15) deliberately mentions that 'the aim of literature courses at Universities is to produce people capable of making literary critical statements". Another similar reason is given by McGarrell (n.d) that "literature allows students to encounter the ideas and experiences throughout history." This explicitly encourages them to appreciate literature and place them in diverse intelligence frameworks that will noticeably lead to a critical thinking towards every problem they are going to face in life. Based on McGarrell opinion, students would be provided with vast ideas 
and problems of the past or even the present, I would rather add, which will give students an overview to see the world not only through their own eyes but also observe and become aware of any divergence that exist through the 'wise' eyes.

In the same way, Temple (n.d.) summarizes a Russian teacher's opinion in an address to teachers-to-be that 'the academic tradition' of teaching literature is based on "philology science" and that students are encouraged to read literature in order to get the idea of style and logic of the literature. Consequently, the teachers would regard the necessity of analyzing literature on their moral value as well as its aesthetic content which is given a term as 'upbringing'.

The term 'upbringing' implicitly reveals the condition of becoming mature through guidance and attention. This is true that educating does not merely mean physical action of giving materials to be learnt but most importantly is to educate them mentally and spiritually. Therefore, for literature teachers, strongly upholding moral value that is contained in literature as an education material is really of intelligent consideration.

Additionally, there could be two main points of teaching literature to students i.e. "in order to introduce students to the inherent pleasures and challenges of literature itself... and in order to get at other issues of educational value, using literature as convenient illustration or as case studies." It is also suggested that students would be more encouraged to learn literature when they know that they can get something from literature (The Reading Literature, n.d).

The existence of 'something' underneath literature which is usually assumed as the moral value, in fact, has been frequently questioned and of whether literature is best appreciated through the deep discussion on literature itself or to get it associated with moral and aesthetic values is still debatable. According to Gilman (1971), D.H. Lawrence and L.C. Knights, for instance, view literary works as having something beyond the works themselves which neither belong to aesthetic nor recreation, rather to the morality.

There is still an ambiguity in judging literature as well as the hesitance of the relationship between literature and moral value, as Gilman stated "if what is said is of moral significance then it must be evaluated in the same way that any statement about moral matters is evaluated". Furthermore, he also states that there is no way of transferring the soul of literature into moral point of view just as there is no route of literary criticism to lead to sort of moral validity (1971, p. 191-192). 
There are two different views on literature as that of moralism on the one hand (the argument that literature should be determined by its moral value) and autonomism (the argument that literature deserves to be analyzed merely through its aesthetic value) on the other. The hot debate does not appear to stop there as in a later discussion some critics position themselves in the 'in between' of the moralism and autonomism. Anderson and Dean defend the modern autonomism that "an artwork will never be aesthetically better in virtue of its moral strengths, and will never be worse because of its moral defects". Meanwhile, modern moralism supporters argue that "some works of art may be evaluated morally and that sometimes moral defects and/or merits of a work may figure in the aesthetic evaluation of the work" (Peek, 2005).

Nowadays in the new century, a new swift of how a literary criticism could be analyzed and cultivated seemingly opens a discourse of more extensive appreciation to literature. Reviewing on Mark William Roche, McNamara (2005) wrote:

It is notable that Roche chooses to evaluate twentieth and twenty-first century literature and criticism not so much on their own terms but from the more removed perspective of idealist philosophy, sometimes communicated through trans-historical metanarrative on the nature of artistic truth and sometimes through discrete labeling of the universal forms populating his overarching model.

That literature exists as the products of society is believably accepted, therefore it concerns with the aspects of society, namely the writer as the producer, the environment in which literature is made as the milieu and the reader as the consumer. Likewise, literature has its own internal structure which is beautified by the language use. In contrast to this, morality, philosophy, psychology, aesthetics, recreation or any attribute being given to the underneath literature are of significant enrichment of literary works. Also the moral value of a literary work could be regarded as a moral teaching for the people who get in touch with literature either as a pleasure and enjoyment or a literary study. There are often common cynical arguments of judging literature in a society appearing in mass media that literary works of any genre bearing no moral messages for the reader or spectators are usually considered as 'rubbish'. This implies that society implicitly demand the birth of literary works that have moral messages.

In terms of moral effects that literature has given to the people so far appear to be somewhat blurry and needs more proof. In my opinion, people do good deeds 
or have beautiful morality is not merely a result of reading literary works or an attempt to comprehend the text as it contains moral value. In this case, people undergo their own processes of becoming mature persons beautified with wellmannered personality because of many cautions such as well-performed parenting, social interaction as well as religion, I believe. Besides, not everyone would interpret a literary work appropriately such as adapt the good teachings and reject the bad ones; this could be the basic ideas of teaching literature to students to view on the morality issue.

Frye (in McKay, 1982) affirms that literature can raise the feeling of tolerance since readers are carried away into a particular context that can be totally different from their own. In reviewing on the issue of literature study in classrooms, my position is best stated by Singh when he concludes that "Literature can be both personally and socially "useful" to a community of readers, without diminishing or marginalizing its other qualities." It is also suggested that literature should be actively implemented (Singh, 2005). It now becomes clearer that literature, to be made more meaningful and in lines with life, should be wisely and selectively applied in classrooms with teachers as the agent of delivery.

\section{BRINGING LITERATURE INTO LANGUAGE CLASSROOMS}

Language used in literature varies ranging from simple sentence expressions to more complex structures. Regarding the various language levels in each different kind of literary works, teachers and lecturers are required to make some adjustment prior to bringing them into classrooms.

McKay confirms that literature is important to be learned due to the reasons that literature could be used to raise the awareness of language use due to its language discourse and social context, to encourage students' motivation, to promote students' creativity, to increase reading proficiency, to tolerate other culture, and to let their imagination grow (1982, p. 530-531). Literature provides students with the various usage of language for communication, broadens cultural understanding, and promotes language development and competence (Popoola, 2010). Abraham states that literature helps activate the "interpretative power" of students. It exposes students with varieties of English language so that students can learn the language used in communicative situation. It can also be "the source of inspiration and motivation from which students may develop an interest for 
practical criticism" (2010, p. 80). In other words, literature that uses language as its means for idea expressions are in fact samples of language use for communicating ideas and culture. Varied themes of literature may make students feel the new experience of learning a particular context they have never been involved in before. This might bring huge motivation and challenge to students to learn this new perspective.

Another way to bring literature into classrooms concerns with how to connect literature and life experience of the students. Numerous themes of love and heroism, for instance, may attract students' attention as they may also experience the same thing (Hansen, 1979). This can really be an interesting classroom activities provided teachers or lecturers can modify and design challenging tasks. It does not have to be a literature discussion inside a class, but it can be outdoor classroom activities such as role plays, games, or creative writing. Students can be asked to simply act as the plot in a drama, or they can be required to write a theme song for the theme of the drama. Costume design and setting design can be another fun thing to do.

When referring to the wider meaning of literature such as those in Cambridge Advanced Learner Dictionary that literature is printed material published by a company which is intended to encourage people to buy that company's products or services, teachers or lecturers even have more choices of materials for students' learning. Carter and Nash (in Savvidou, 2004) propose that students can also learn advertisement and headline news because they also use literary language. It then can be made clear that there are huge literary kinds available for use in classrooms and it depends on the teachers or lecturers to improvise them to suit with their school curriculum.

Another form of literature seems to grab more students' attention, namely the electronic literature. As is known, students in this cyber era are stuffed with limitless abundant information and entertainmentcomics, story books, contemporary arts, modern literature which can be freely accessed through the internet. There are so many alternatives that they have their very own right to choose. Besides, whatever available literary works in the internet can also be used as learning materials and teachers or lecturers should select and adjust them. This is where teachers and lecturers' creativity are indeed necessary to formulate and transform those abundant resources into hands-on learning materials. 
It is, therefore, noteworthy to address how such a form of literature can be brought into classrooms in which the students are digital natives and closely connected to the advances of technology. It is in this situation then that teachers or lecturers should take their urgent roles in learning processes. Some may argue that it is the canon that students should learn. However, the fact is that no one would ever be able to force them to love the so called'canon'. Alternatively, learning and appreciating the 'canon' while comparing them to another kind of contemporary literature from the digital world could be somewhat challenging. It can lead students to mingle with wider multicultural, contextual, and global world. Not only will they have more open mind and eyes, but also ultimately understand the 'changing phenomena' and be the 'wise player' in coping with life.

Tsung-Mei (n.d.) proposes an interesting worksheet that is made based on a short story entitled "The Invisible Scar." The worksheet is specially designed to learn a) reading comprehension skills such as guessing meaning from context, making inferences, synonyms, and through the short story; b) speaking skills through recording the students' voice and role play; c) writing skills that involve creative writing such as changing the end of the story. The activities in the worksheet seem to explore more students' competencies and create fun learning regarding the various classroom activities involved.

Tsung-Mei's worksheet sample may become the good sample of bringing literature into a language classroom. The worksheet seems to comprehensively generate learning activities using literature to help students gain better language proficiencies. Her sample is like 'putting theories into practice' that is supported by the finding of Tasneen (n.d.). Tasneen research on how literature can help students develop their language competencies shows that literature can be used to teach vocabulary and develop four basic language skills of reading, writing, listening, and speaking (n.d.). Therefore, evidence exists that literature is useful for helping learners learn and improve language proficiency.

Besides the many available literary works for learning a language, there are precautions that teachers or lecturers have to consider in term of linguistic difficulties, vocabularies, and interpretation (O'Sullivan, 1991). Carter suggests that literature and language can be taught at the same time as long as learning objectives are appropriately designed. For language classrooms, language should become the main learning objective (in O'Sullivan, 1991). Another view on bringing literature into classrooms concerns with the objective of teaching and 
learning process. The learning objectives should be "the study of words, idioms and syntax at the highest level of thought and imagination." (Abraham, 2010). In 
Ohmann, R.(2004). "Teaching and Studying Literature at the end of Ideology". An excerpt from the book English in America: A Radical View of the profession. 02-Aug-2004 09:28:50 EDT Retrieved from http://www.writing.upenn.edu/ afilreis/50s/ohmann.html

Poole, S. C. (1999). An Introduction to Linguistics. New York and Great Britain: Palgrave

Peek, E. (2005). Ethical Criticism of Arts. The Internet Encyclopedia of Philosophy. 2005. Retrieved from http://www.iep.utm.edu/a/art-eth.htm

Singh, A. (2005). Why Teach Literature part 2: The Reading Experience Response. January 10, 2005. Retrieved from http://www.lehigh.edu/ amsp/2005/01/ why-teach-literature-part2.reading.html

Tasneen, W. (n.d.). Literary Texts in the Language Classroom: a Study of Teachers' and Students' views at International schools in Bangkok. Asian EFL Journal, Vol. 12 Issue 4Temple, C. Why We Teach Literature. Retrieved from http://www.uni.edu/coe/rwct/resources /why teaching literature.html

Tsung-Mei, L. (n.d.) Using Literature in the Language ClassroomWriting Your Own Short Stories and Creating Your Own Worksheets (A Sample). Retrieved on February 13, 2013 from http://lib.csghs.tp.edu.tw 
Journal of English and Education, Vol. 6 No.2 - December 2012 